\author{
P. FISCHER ${ }^{1,}$ \\ H. LEBER ${ }^{1}$ \\ V. ROMANO ${ }^{1}$ \\ H.P. WEBER ${ }^{1}$ \\ N.P. KARAPATIS ${ }^{2}$ \\ C. ANDRÉ ${ }^{2}$ \\ R. GLARDON ${ }^{2}$
}

\section{Microstructure of near-infrared pulsed laser sintered titanium samples}

\author{
${ }^{1}$ Institute of Applied Physics, Laser Materials Processing, University of Bern, Switzerland \\ ${ }^{2}$ Laboratory for Production Management and Processes, Mechanical Engineering Department, \\ EPFL Lausanne, Switzerland
}

Received: 2 December 2002/Accepted: 16 April 2003
Published online: 11 June 2003 • C Springer-Verlag 2003

ABSTRACT The microstructure and material properties of nearinfrared pulsed laser sintered titanium have been investigated. Several analyses of the selectively laser sintered titanium powder, using characterisation techniques such as compressive strength, microhardness, energy-dispersive X-ray microanalysis, X-ray diffractometry and scanning electron microscopy analysis, allowed the metallurgical description of the sintering process. Only partial melting in a narrow surface layer took place, whereas most of the material stayed clearly below the melting temperature.

PACS 42.62.Cf; 81.05.Bx; 81.05.Rm; 81.20.Ev

1

\section{Introduction}

Since its invention in 1995, much effort has been made to improve the selective laser sintering (SLS) process. SLS can be used for rapid prototyping (RP) by layered manufacturing (LM) and it allows the direct employment of the material of the final work piece, which makes SLS suitable for rapid tooling (RT). If the material used is a metal powder, the process is called direct metal laser sintering (DMLS) and works as follows.

A laser beam that scans the surface of a loose powder bed, following the geometry of a sliced CAD file, consolidates the freeform. Then a further layer of the powder is brought on, and the next layer is sintered. This technique is very promising as almost any 3D shape can be produced, without the need of prefabrication of part-specific tools [1]. A precision of less than $50 \mu \mathrm{m}$ can be obtained at the moment.

Pulsed laser sintering has been shown to be the key towards further improvement of the precision due to its different interaction manner: as described in our model for the interaction of near-infrared laser pulses in selective laser sintering [2], the process can be optimised by adapting the pulse duration to the powder size in such a way that the heat diffuses much less than the grain radius during the interacting pulse. In this case, only the surfaces of the individual grains are melted. Therefore, only a small fraction of the material is melted and

Fax: +41-31/631-3765, E-mail: fischer@iap.unibe.ch a similar reduction of the energy needed can be expected for the sintering process.

In this article, we report the metallurgical analysis of sintered titanium specimens. Micrographs have been obtained with both optical and scanning electron microscopes, and Xray diffractometry, microhardness tests and ultimate compressive strength tests have been performed. With this information, a history of the microstructure of the material can be obtained.

\section{$2 \quad$ Materials and methods}

Due to their desirable properties, titanium and its alloys are finding widespread use in industry. The aerospace industry still provides the major market. In addition, titanium (and its alloys) is also used in the automotive and chemical industries. Notably, titanium possesses a low density located between that of aluminium and iron, whereas its strength is situated rather close to that of steel. Therefore the strength to weight ratio of titanium is very attractive. In many environments titanium has excellent corrosion resistance, which also is reflected in its biocompatibility. Therefore titanium also finds widespread use in medical techniques and implants.

In this article, we investigate the microstructures of the initial powder, of the sintering on a powder bed (a layer of several millimetres) and of the sintering of a three-dimensional specimen where many layers (each of 50- $\mu$ m thickness) are subsequently sintered on top of each other. The main difference between the latter two cases is the difference in the lower thermal conductivity between the underlying loose powder and the sintered layer.

\section{$2.1 \quad$ Material characterisation}

The physical properties of the employed powder were described in $[2,3]$. Impurities in the powder-delivery system result in traces of nickel localised in the binding material, as found by energy-dispersive X-ray microanalysis (EDX). However, they are too low to be detected by X-ray diffractometry.

2.1.1 Statistics on powder morphology. A commercial pure titanium powder, provided by Pyrogenesis Co., was used for selective laser sintering. The titanium particles are spherical, and their grain sizes have a Gaussian distribution with the 
mean value near $8 \mu \mathrm{m}$ and a maximum grain size of about $30 \mu \mathrm{m}$. The layer density of the Pyrogenesis titanium powder is $2931.5 \mathrm{~kg} / \mathrm{m}^{3}$, corresponding to a volume ratio of $64.6 \%$ compared to bulk titanium (density $4540 \mathrm{~kg} / \mathrm{m}^{3}$ ).

2.1.2 Optical properties. The amount of the back-scattered $\mathrm{Nd}$ :YAG laser radiation $(1.064 \mu \mathrm{m})$ interacting with the titanium powder is $70 \%$. The optical penetration depth (OPD, defined as the depth where the intensity of the radiation is at $1 /$ e of the not-back-scattered intensity of the Nd:YAG radiation) was measured to be $63 \mu \mathrm{m}$.

The optical penetration depth of near-infrared radiation $(1.064 \mu \mathrm{m})$ into the bulk material, which becomes relevant in the interaction of each single grain with short laser pulses, is $6 \mathrm{~nm}$ for titanium.

2.1.3 Thermal properties. The thermal conductivity $k$ of the titanium powder was found to be $k_{\text {titanium powder }}=1.45 \mathrm{~W} / \mathrm{mK}$. It is a key parameter as the heat-diffusivity value $\kappa=k / \varrho C$ (where $\varrho$ denotes the density of the powder and $C$ its heat capacity) controls temperature evolution in the powder.

The molar mass of elementary titanium is $M=$ $47.9 \times 10^{-3} \mathrm{~kg} / \mathrm{mol}$. The enthalpy of fusion is $H_{\text {fusion }}=$ $20.9 \mathrm{~kJ} / \mathrm{mol}$ (or $436.4 \mathrm{~kJ} / \mathrm{kg}$ ) and the enthalpy of vaporisation is $H_{\text {vap }}=428.9 \mathrm{~kJ} / \mathrm{mol}$ (or $8955 \mathrm{~kJ} / \mathrm{kg}$ ).

2.1.4 Phase properties and phase transitions of titanium. Table 1 lists the phase properties of elementary titanium at normal pressure. In the solid state, two different phases occur: firstly, the $\alpha$-titanium phase, which is hexagonal close packed (hcp) and stable at temperatures below $1155 \mathrm{~K}$. At this temperature a polymorphic phase transformation takes place and at temperatures above $1155 \mathrm{~K}$ the $\beta$-titanium phase dominates, which is body centred cubic (bcc).

\begin{tabular}{|c|c|c|c|c|}
\hline \multirow[t]{2}{*}{ Titanium } & \multicolumn{2}{|c|}{ Solid phases } & \multirow[t]{2}{*}{ Liquid phase } & \multirow[t]{2}{*}{ Gas phase } \\
\hline & $\alpha-\mathrm{Ti}$ & $\beta-\mathrm{Ti}$ & & \\
\hline Crystalline stru & hcp & De & & \\
\hline Temperature range & $<1155 \mathrm{~K}$ & $>1155 \mathrm{~K}$ & $>1933 \mathrm{~K}$ & $>3560 \mathrm{~K}$ \\
\hline
\end{tabular}

TABLE 1 Summary of the phases of titanium with transition temperatures at normal pressure

\section{2}

\section{Laser sources}

For the sintering process, a Nd:YAG laser was used. Depending on the scan speed and beam diameter on the surface of the powder level, the laser was driven at average powers of $3 \mathrm{~W}(100-\mu \mathrm{m}$ spot size, $5-\mathrm{kHz}$ repetition rate, $1-\mathrm{mm} / \mathrm{s}$ scan speed) and $17 \mathrm{~W}(420-\mu \mathrm{m}$ spot size, $50-\mathrm{kHz}$ repetition rate, $40-\mathrm{mm} / \mathrm{s}$ scan speed) where in both cases the energy per pulse and the number of pulses per laser spot were comparable.

\subsection{Methods for analysis}

A short description of the methods for analysis of the sintered samples is presented in this section.

2.3.1 Metallographic preparation. For the microscopy of the initial powder as well as of the sintered plates, the specimens are mounted in an electrically conductive duroplast (a polymer which consolidates under elevated temperature and pressure). The metallographic samples are $\mathrm{SiC}$ ground, diamond polished and etched by immersion in an aqueous solution of nitric and hydrofluoric acids.

2.3.2 Microscopy and microanalysis. The metallographically prepared samples were analysed with an optical phasecontrast microscope as well as by scanning electron microscopy (SEM, International Scientific Instruments ISI-DS $130 S$ ) with integrated energy-dispersive $X$-ray microanalysis (EDX).

2.3.3 X-ray diffractometry. A comparison of the crystalline structures of the unsintered powder and the sintered plates can be obtained by X-ray diffractometry.

2.3.4 Microhardness testing. The microhardness was tested by the Vickers hardness testing method, according to the ISO 6507-1 standard. Therefore, a pyramid with well-defined angle $\left(136^{\circ}\right)$ between the planes is placed on the specimen and loaded with different masses. The Vickers hardness is then defined as the quotient of test load and area of produced indentation. The unit is HV, followed by the load in $\mathrm{kg}$, and is proportional to $\mathrm{N} / \mathrm{m}^{2}$.

2.3.5 Ultimate compression test. For this purpose, a sintered cylinder ( $7.45 \mathrm{~mm}$ in diameter) is pressed until visible cracks appear or it is destroyed. During this testing, both the displacement of one of the dies (corresponding to the height reduction) and the applied force are measured. The test was performed with a die-displacement speed of $1 \mathrm{~mm} / \mathrm{min}$.

\section{$3 \quad$ Results}

The investigation strategy consists of three main steps: (i) investigation of the microstructure of the initial powder, (ii) investigation of the microstructure of a powder bed sintered specimen and (iii) investigation of the microstructure of a three-dimensionally sintered specimen when many layers are subsequently sintered on top of each other. The main difference between the samples described in Sect. 3.2 (powder bed) and Sect. 3.3 (three-dimensional specimen) is given by the physical properties of the underlying material. In powderbed experiments the underlying material is a loose powder, whereas for the three-dimensional specimen (cylinders) the underlying material is sintered. In the second case, the connections between the grains of the layer beneath lead to an increased thermal conductivity and therefore a more efficient transport of heat away from the interacting zone.

\subsection{Initial titanium powder}

The pictures in this paragraph show micrographs of the chemically etched specimen. Figure 1 was obtained with an optical Nomarski microscope with polarised light in reflection. It pictures a cross section of unsintered titanium spheres of different sizes. The powder was produced by a titanium wire fed through a plasma jet in inert atmosphere. The wire is molten, atomised and recrystallised to spherical particles. 


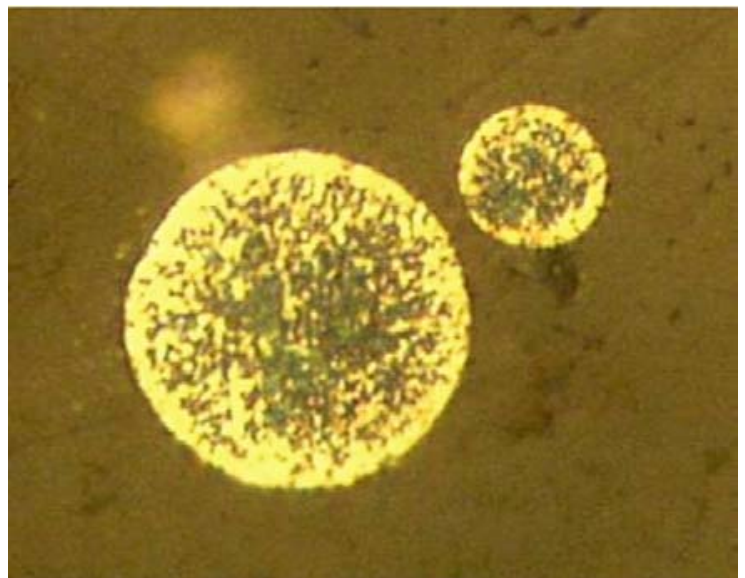

FIGURE 1 Optical micrograph of an unsintered titanium sphere after chemical etching

The cooling takes place in a time scale leading to the formation of very fine granular primary $\alpha$-phase grains. The

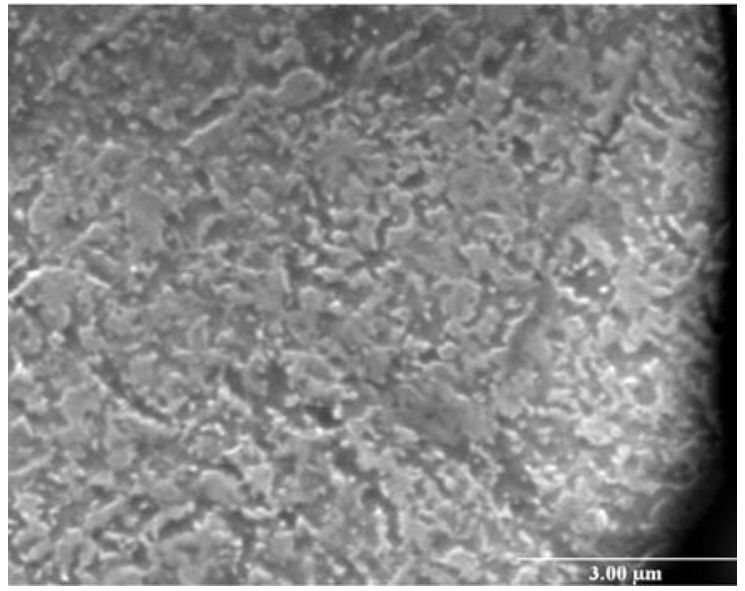

FIGURE 2 SEM micrograph of an unsintered titanium sphere after chemical etching. Very fine primary $\alpha$-grains (dark) in a matrix of martensitic transformed $\beta$ - to $\alpha^{\prime}$-phase

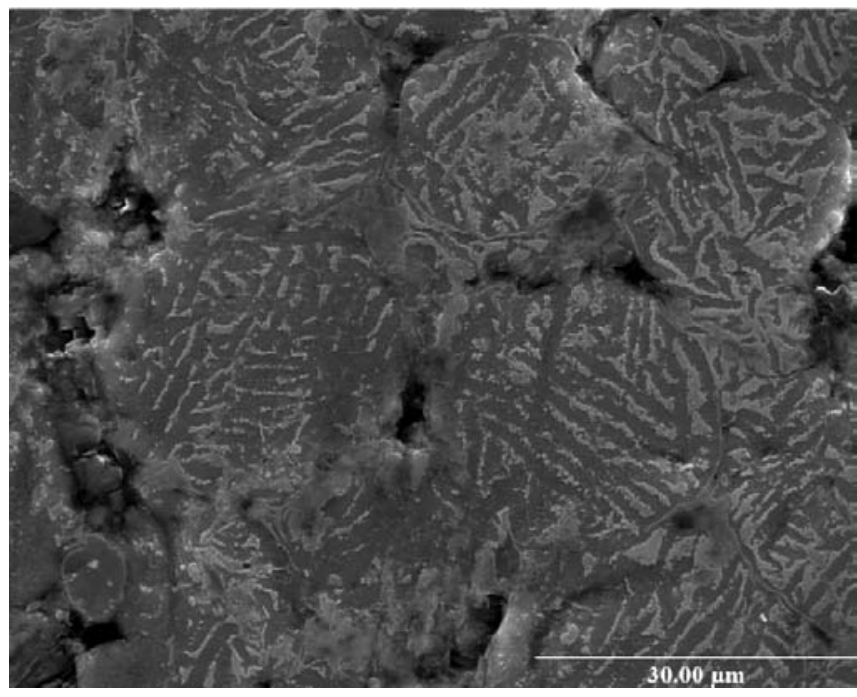

FIGURE 4 Widmannstätten $\alpha$-phases stuctures (dark) in tranformed $\alpha^{\prime}$-phase (bright) in different magnifications observed on powder bed sintered titanium plates remaining $\beta$-phase undergoes a martensitic transformation as is revealed by the SEM analysis pictured in Fig. 2.

\subsection{Powder-bed experiments}

Figure 3 pictures a typical powder bed sintered titanium plate. The needle-like primary $\alpha$-phase grains (bright) are dominant in a matrix of martensitically transformed $\alpha^{\prime}$ phase (dark).

Figure 4a shows a SEM micrograph of a sintered titanium plate produced on a powder bed. The grain boundaries are still visible.

The same situation at higher magnification is pictured in Fig. 4b. Here one can see that the Widmannstätten phases overlap the powder-grain boundaries in the sintered plates.

\section{3}

\section{Three-dimensional specimen}

Figure 5 pictures a metallographic cut of a sintered titanium plate. The cross section can be divided into two dif-

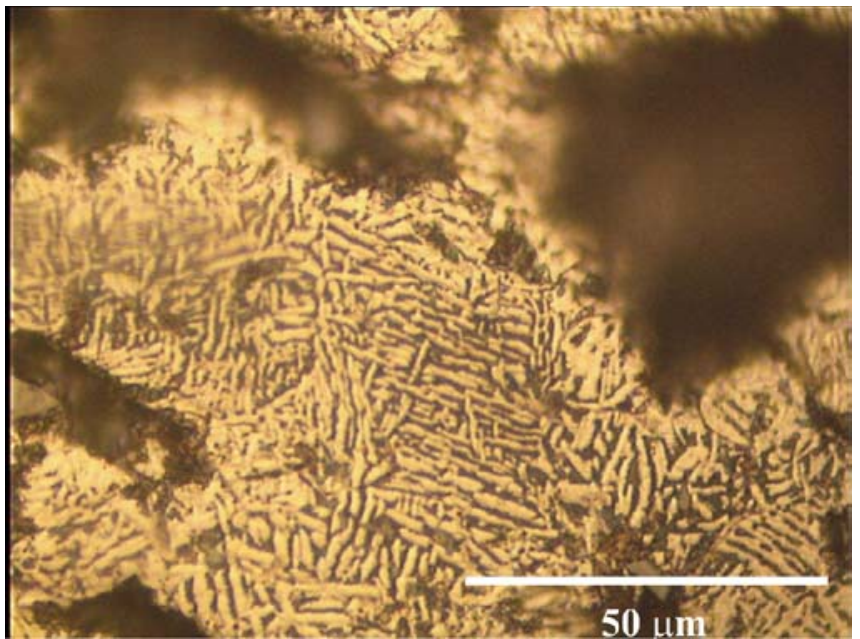

FIGURE 3 Optical micrograph of a sintered titanium plate produced on a powder bed

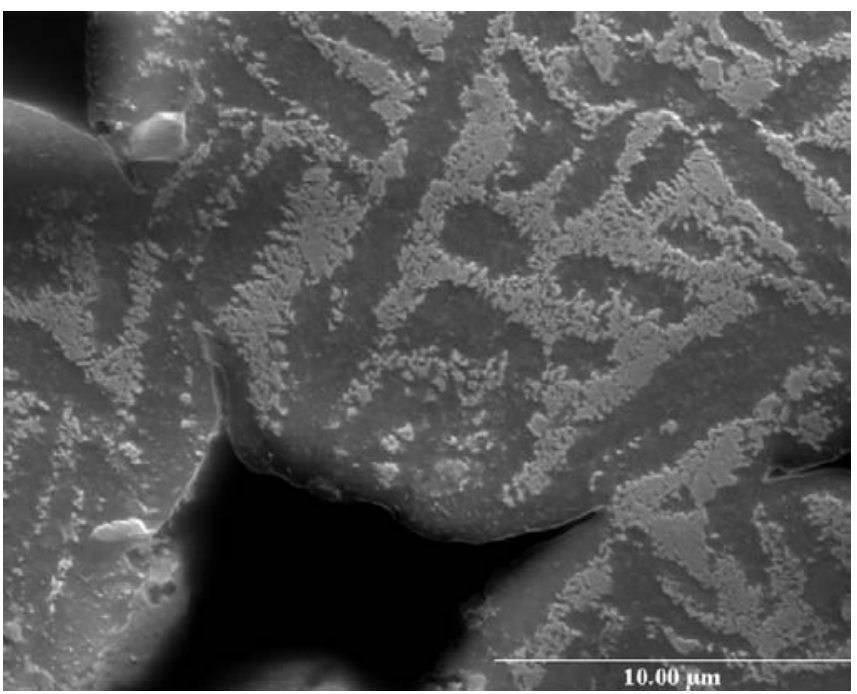
ferent regions: 


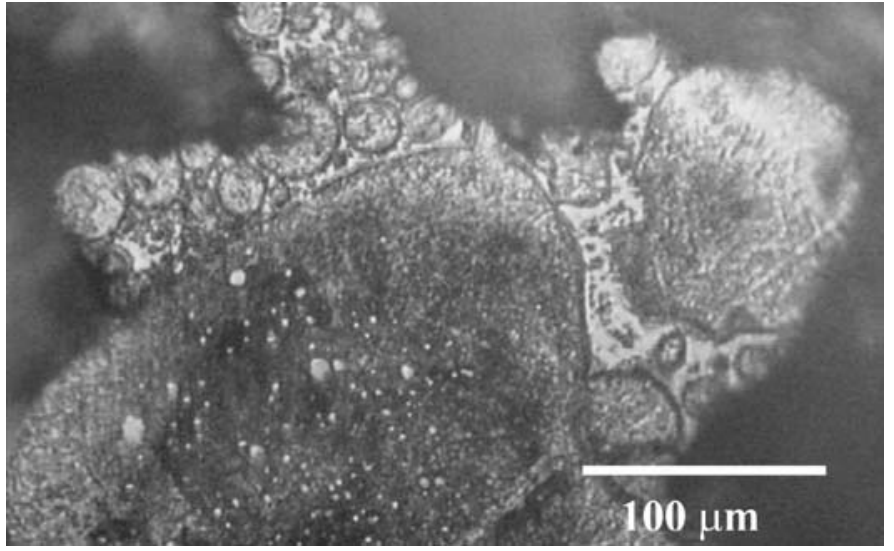

a

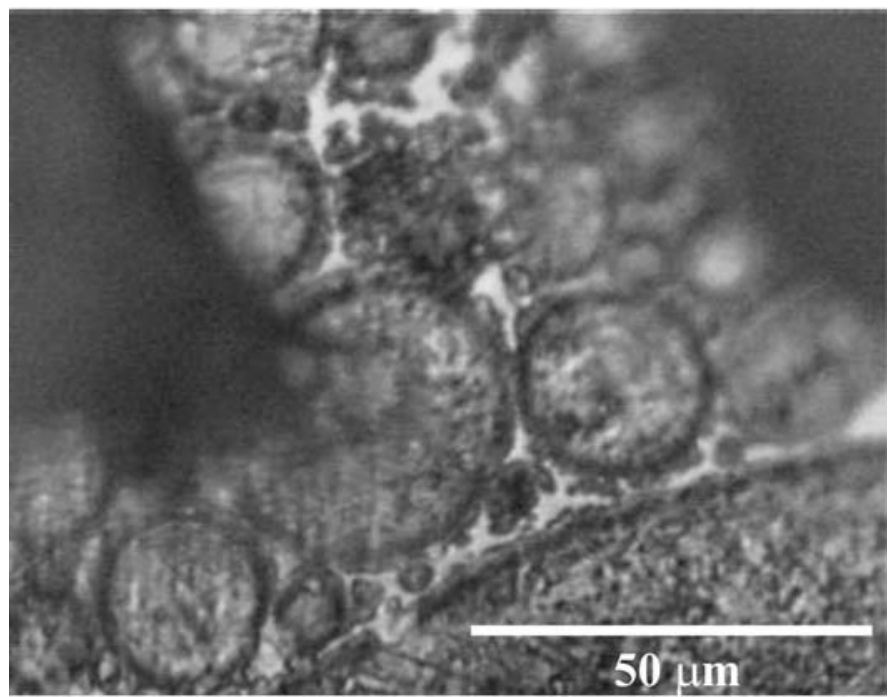

a

Region 1: a nearly homogeneous, bulk-like microstructure, similar to the initial microstructure of the unsintered powder. The grain boundaries are no longer visible.

Region 2: a cluster of distinguishable grains, connected by resolidified liquid.

Figure 6 shows the same cluster of Fig. 5, region 2 at a higher magnification. It is more clearly visible that the microstructure is very different in between the grains.

One can again divide Fig. 6a into three different regions (as pictured in Fig. 6b): core of the grains (1), surface of the grains (2) and 'binding material' (3). To ensure that the appearance of the surface layer of the grains in Fig. 6 (region 2) is not due to an artefact (edge rounding after polishing), a more detailed micrograph was obtained by scanning electron microscopy. Figures 7 and 8 show all the regions mentioned above at two different magnifications. Figs. 7 and 8 confirm the impression gained from the optical microscopy. The surface-layer zone is not due to edge rounding. The socalled 'binding material' represents a eutectic or eutectoid microstructure.

The energy-dispersive X-ray microanalysis (EDX) reveals an important amount of nickel in the binder material (due to impurities in the powder-delivery system). The primary solid-
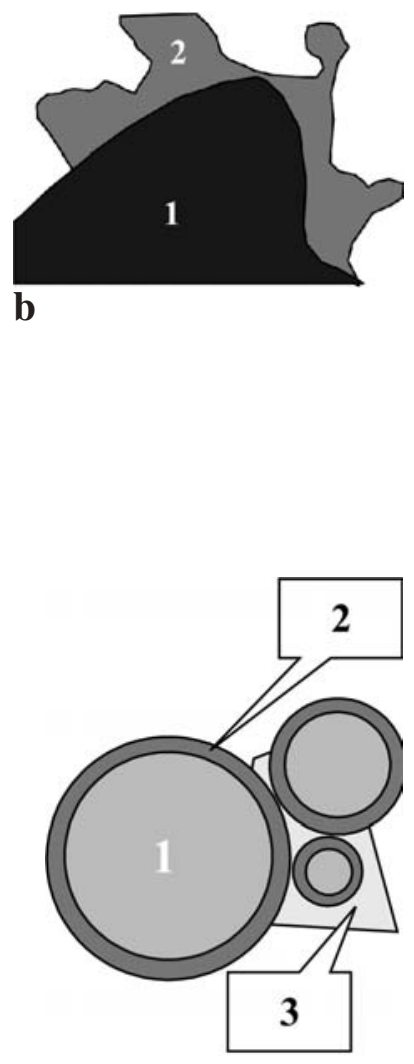

b
FIGURE 5 a Sintered titanium plates after mechanical cutting and etching, $\mathbf{b}$ different sections of the total plate
FIGURE 6 Sintered titanium plates after mechanical cutting and etching: a micrograph of different regions in between the cluster region, b different regions of the total plate

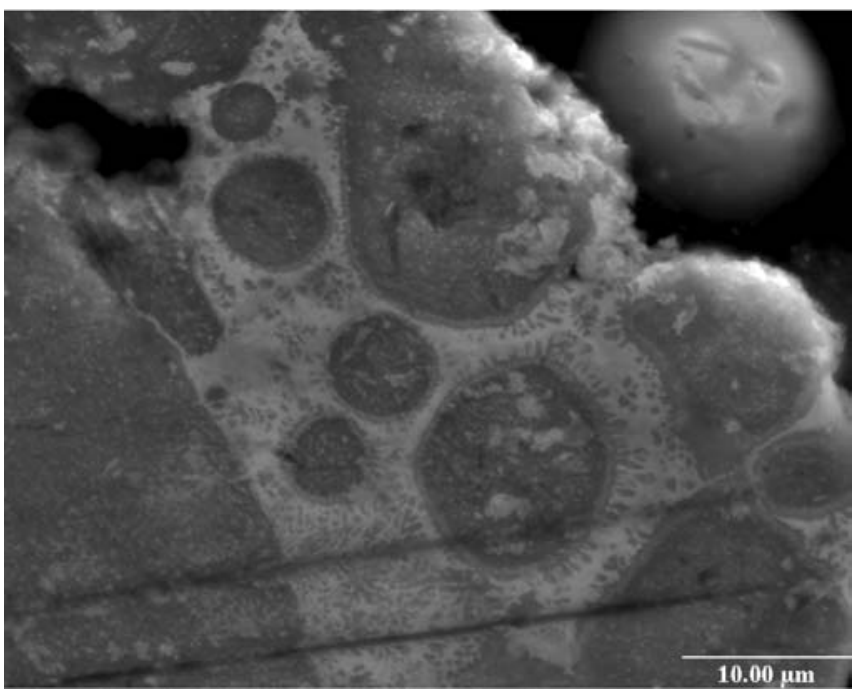

FIGURE 7 SEM micrograph

ified $\beta$-phase (dark grains in Fig. 8) is a solid solution of $\mathrm{Ni}$ in Ti. The amount of nickel measured by the semi-quantitative EDX analysis is $7.5 \pm 2.9$ at. \%. The remaining liquid having the eutectic composition solidifies by a eutectic transform- 


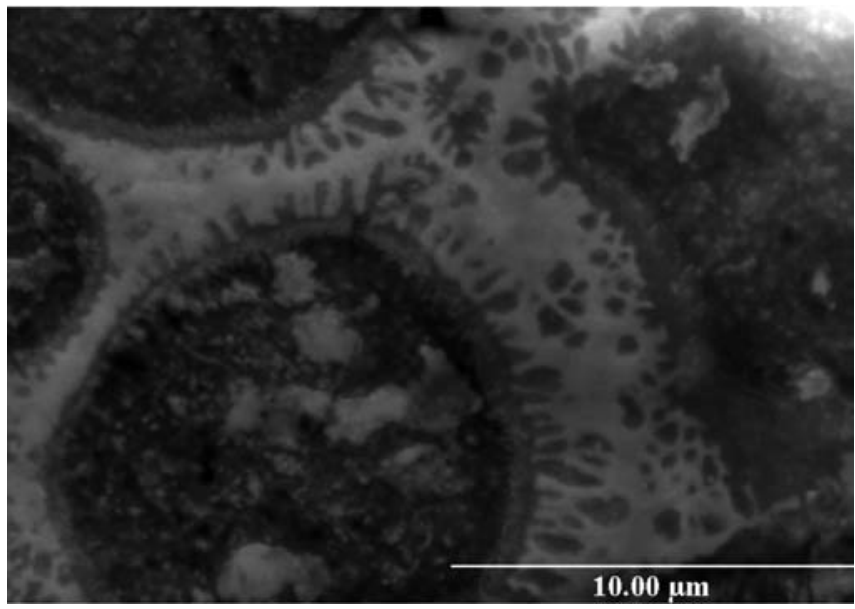

FIGURE 8 SEM micrograph

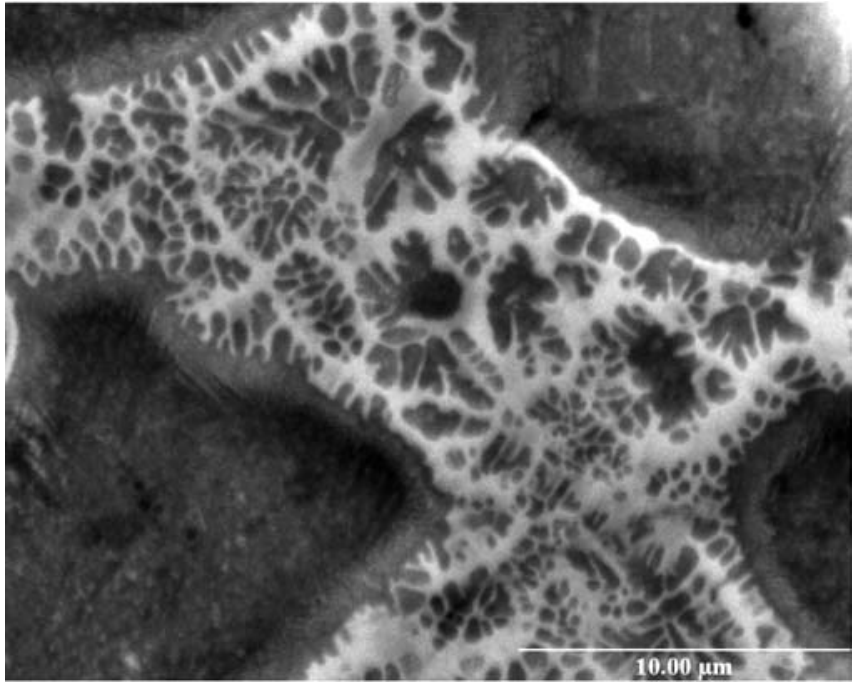

FIGURE 9 SEM micrograph of the eutectic or eutectoid microstructure of the binding matirial

ation consisting of $\beta$-phase and the intermetallic compound $\mathrm{NiTi}_{2}$ (bright constituent in Fig. 8). The EDX analyses revealed a portion of $17.8 \pm 3.7$ at. \% Ni. No nickel was found in

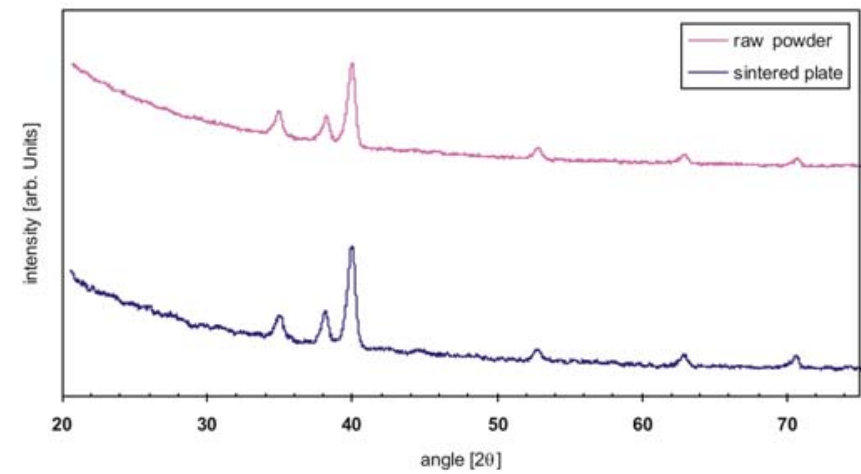

FIGURE $10 \mathrm{X}$-ray diffractometer analysis of unsintered (upper) and sintered (lower) titanium powder

the surface layer or in the centre of the powder grains. Figure 9 shows a similar picture as Fig. 8. It seems that the dark-texture part is bigger than in Fig. 8 .

\subsection{X-ray diffractometer}

The X-ray diffractometer (at $\lambda=1.5405 \AA$ ) shows that raw powder and the sintered titanium plate have the same crystalline structure, as no difference between the upper and lower curves in Fig. 10 is visible.

The three main peaks at $35^{\circ}, 38^{\circ}$ and $40^{\circ}$ correspond to the atom-layer distances $d=2.56 \AA, 2.34 \AA$ and $2.24 \AA$ respectively, which coincide with the literature values for the hexagonal $\alpha$-titanium phase stable at room temperature.

\section{5}

\section{Microhardness measurements}

Both the initial powder and the sintered plates were microhardness measured according to the Vickers microhardness test (DIN EN ISO 6507-1). The loads used were $10 \mathrm{~g}$ and $50 \mathrm{~g}$.

The initial powder showed a Vickers hardness of $170-220 \mathrm{HV} 0.01$. The literature value given by the provider is $200 \mathrm{HV}$ [5].

According to the classification made in Fig. 5, the homogenous molten structure with nearly bulk-like density (region 1) showed an increased hardness of 250-340 HV 0.05 .

Hardness of Ti Powder and Laser Sintered Plate \# 1

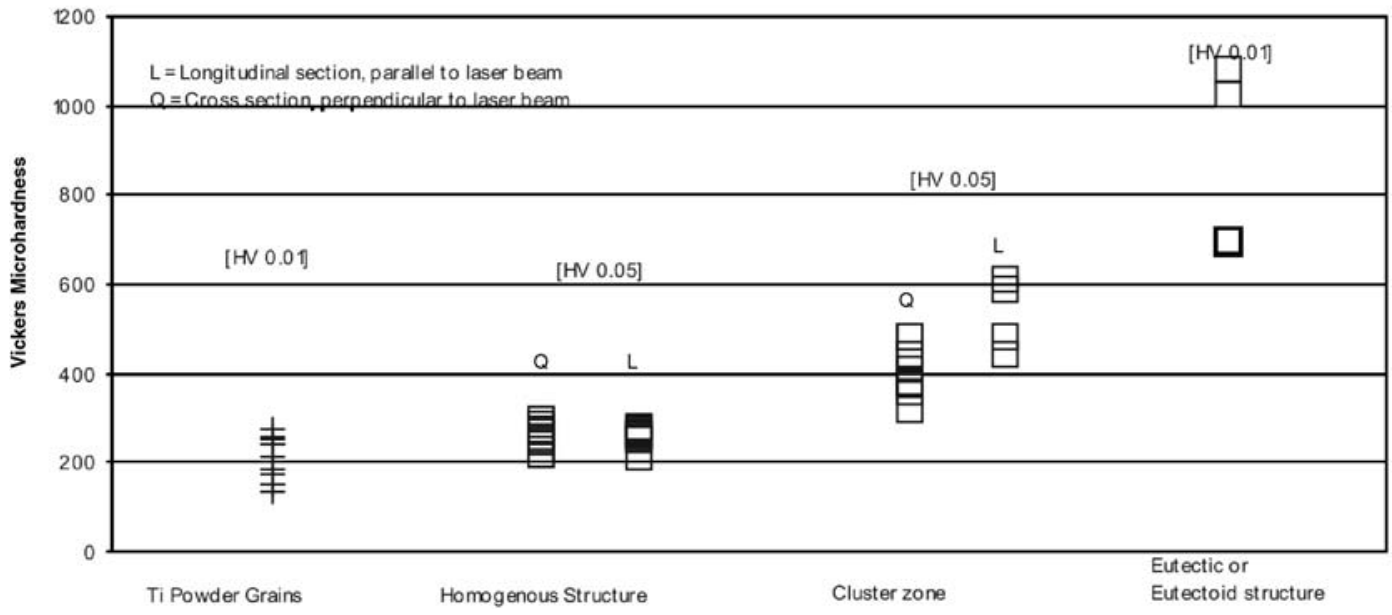

FIGURE 11 Microhardness measurement of the unsintered powder (left) and the sintered plates 


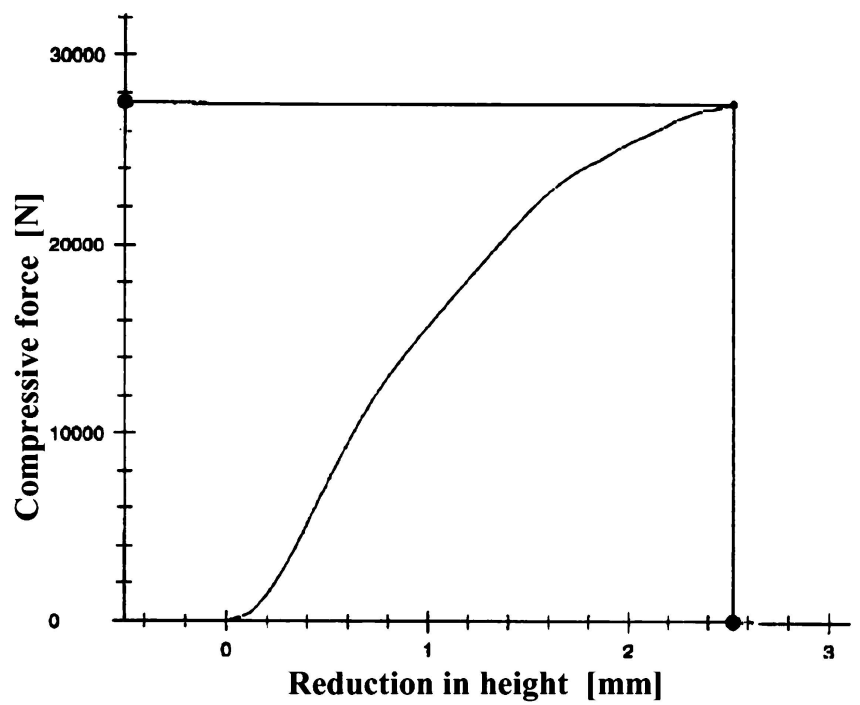

FIGURE 12 Ultimate compressive strength testing

The mentioned cluster zone (region 2) features a hardness of 400-435 HV 0.05 and the eutectic or eutectoid zone 700-1100 HV 0.01. Those values are also pictured in Fig. 11.

For comparison, the Vickers hardness for bulk titanium is $60 \mathrm{HV}[6]$.

In addition to the Vickers microhardness measurements, ultimate compression tests were performed.

The maximum stress (which is equal to the ultimate tensile strength) was found to be $\sigma_{\max } \approx 600 \mathrm{MPa}$.

The compressive yield strength, which is the point where the curve shown in Fig. 12 deviates from the linear dependency by Hooke's law, is reached at $\sigma_{\mathrm{p}}=260 \mathrm{Mpa}$; afterwards irreversible or plastic deformation takes place.

4

\section{Discussion}

The initial situation is the same for both specimens described in Sects. 3.2 and 3.3: a very narrow surface layer is at much higher temperature and molten.
But the cooling rate, which differs due to the different thermal properties, determines the final crystalline microstructure of the specimen.

At lower cooling rates (left-hand side of Fig. 13) both the solidification and the polymorphic transformation take place more slowly and fewer primary $\alpha$-phase grains grow to a larger size, forming a needle-like microstructure. This microstructure, also called the Widmannstätten structure, is visible in Figs. 6 and 7. In this case, the surface layer is resolidified while the inner part of the grains is at a temperature between the temperature of the polymorphic phase transition $(\alpha \rightarrow \beta)$ and the melting temperature. The remaining $\beta$-phase in the interspaces of the Widmannstätten grains undergoes a martensitic transformation.

At higher cooling rates (right-hand side of Fig. 13), the material is quenched; thus a large amount of grains nucleate, which leads to fine granular primary $\alpha$-grains. This is the case in the initial powder and the three-dimensionally sintered specimens pictured in Figs. 5-9. Generally, two different regions are visible:

- Region 1 was homogeneously molten and resolidified. The whole region 1 has the same crystalline structure as the initial unsintered grains. Therefore, we assume that the cooling rate of the molten and resolidified material during further cooling across the polymorphic transformation temperature can be compared to those of the plasma atomised and rapidly solidified powder grains.

- Region 2 is a cluster of several powder grains, bound by the molten surface layer of the single grains and some smaller grains which were totally melted before resolidification. This region is very interesting and therefore subdivided into three sections:

- Section 1 is the centre of the spheres that remained in their original crystalline structure as no melting occurred.

- Section 2 is the surface layer where a coexistence of melt and solid state occurred during the pulsed interaction at elevated skin temperature. The thickness of this layer is between $700 \mathrm{~nm}$ and $1 \mu \mathrm{m}$. Calculation of the heat-diffusion length for a semi-infinite target results in
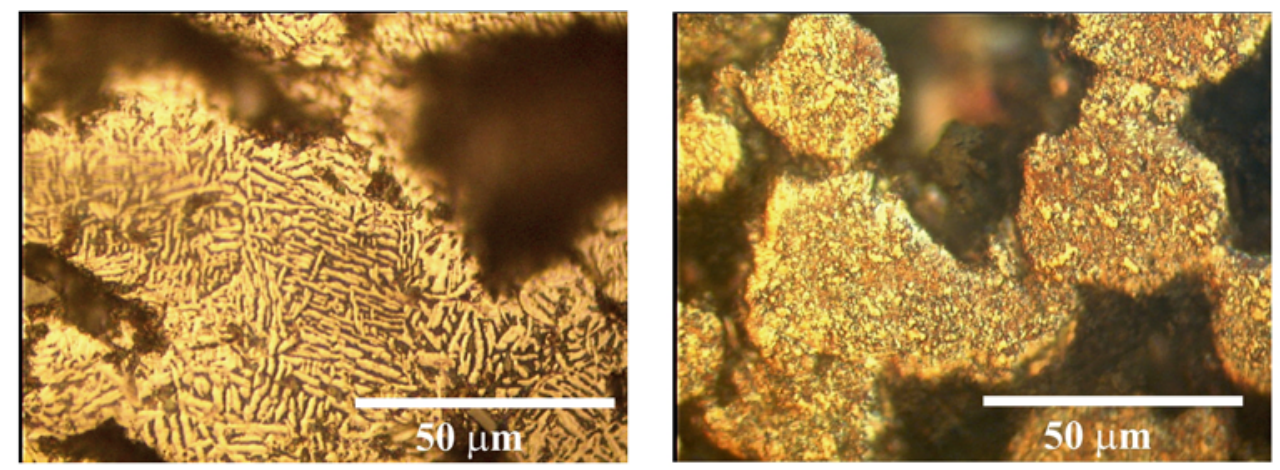

Slow

fast

cooling

time

FIGURE 13 Influence of the cooling time on the crystalline microstructure. Left-hand side: slow cooling leads to Widmannstätten structures. Right-hand side: fast cooling leads to quenching of the crystalline microstructure and therefore to fine primary $\alpha$-grains 
$z_{\mathrm{D}}=2.36 \mu \mathrm{m}\left(\right.$ for $\left.\kappa=9.3 \times 10^{-6} \mathrm{~m}^{2} / \mathrm{s}\right)$. For a sphere, the expected value should be two or three times lower, which corresponds very well with the observed layer thickness.

- Section 3 corresponds to the region where a binding neck due to molten and resolidified material connects the neighbouring grains. This region shows a eutectic microstructure: impurities tend to be enriched in the liquid phase, therefore this connecting layer possesses different mechanical properties as was also shown in Sect. 3.5. In addition, EDX analysis reveals an important amount of nickel, which is considered to be alloyed to titanium. The presence of the intermetallic compound $\mathrm{NiTi}_{2}$ explains the strong increase of the microhardness.

The solidification mechanism and the subsequent transformation behaviour can be explained as follows.

Upon cooling, the liquid Ti alloy containing an important proportion of $\mathrm{Ni}$ reaches the liquidus temperature, which is much below the solidification temperature of pure Ti. The primary solidified $\beta$-phase (dark grains in Fig. 8) having the cfc lattice is a solid solution of $\mathrm{Ni}$ in $\mathrm{Ti}$. The amount of nickel measured by the semi-quantitative EDX analysis is $7.5 \pm 2.9$ at. \%. This proportion is lower than the content of the liquid alloy. During further cooling the amount of the primary $\beta$-phase increases whereas the quantity of liquid decreases. At the same time the primary solid as well as the remaining liquid become richer in Ni. Once the eutectic temperature, $942{ }^{\circ} \mathrm{C}$ according to the binary equilibrium phase diagram, is reached the remaining liquid having the eutectic composition solidifies by a eutectic transformation consisting of $\beta$-phase and the intermetallic compound $\mathrm{NiTi}_{2}$ (bright constituent in Fig. 8). The EDX analyses revealed a proportion of $17.8 \pm 3.7$ at. $\% \mathrm{Ni}$. The effective amount of $\mathrm{Ni}$ in the liquid Ti-Ni alloy must be between the contents of the primary solid and the remaining liquid just before its solidification. The alloy composition could be estimated more precisely by quantifying the proportions of the observed microconstituents. The rather high cooling rate decreases the solidus and the eutectic temperatures; it also removes the eutectic composition of $17.8 \pm$ 3.7 at. \% of $\mathrm{Ni}$, determined by EDX, from the plotted value in the binary equilibrium diagram in Fig. 14 (25.9 at.\% of $\mathrm{Ni}$ ).

During further cooling to room temperature the primary $\beta$-phase as well as the products of the eutectic transformation will undergo a eutectoid transformation, a consequence of the allotropic behaviour of the Ti. The $\beta$-Ti transforms to $\alpha$-Ti or to $\alpha^{\prime}$-Ti according to a martensitic transformation.

The metallographic and SEM investigation reveal that the surface layer of the sintered grains exhibits a different microstructure than the core. The surface was melted by the laser-beam interaction and resolidified. In Fig. 8 we detect that the molten surface layer of the single grain remained compact. It means that there was no homogenisation of the molten surface layer with the liquid so-called binder alloy. However, we can assume that some diffusion of the alloyed $\mathrm{Ni}$ into the surface layer occurred, which is responsible for the observed two-constituent microstructure. An overview of the phase transitions during the sintering process is pictured in Fig. 14.

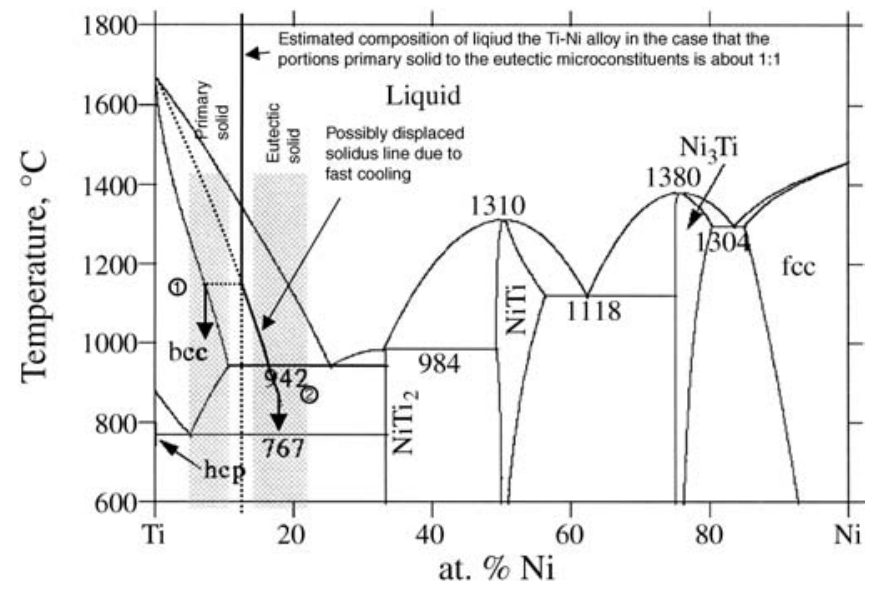

Notices: The measured semi-quantitative portions in masse-\% by EDX have been converted into atomic-\%

(1) Primary solid: $\quad \mathrm{L} \rightarrow \beta+\mathrm{L}$

(2) Eutectic reaction: $\mathrm{L} \rightarrow \beta+\mathrm{NiTi}_{2}$ (final solidification)

FIGURE 14 Binary phase diagram of the system Titanium and Nickel

\subsection{Hardness, compressive and tensile strength}

It is known that the Vickers hardness is often proportional to the tensile strength (according to DIN 50 150). The ultimate tensile strength of pure bulk titanium is $R_{m}=$ $220 \mathrm{MPa}$ [6], whereas it is in the range from 250 to $400 \mathrm{MPa}$ for a 'traditional' sintered specimen [4].

The ratio of the tensile strength and the Vickers hardness is $220 / 60=3.66$.

If the sintered cylinder had a bulk-like density, its ultimate tensile strength would thus be 3.66 times the average Vickers hardness of $260 \mathrm{HV}$, which equals $950 \mathrm{MPa}$. If this value is scaled with the ratio of the densities of the specimen and bulk material, which was measured to be about $72 \%$, one obtains an ultimate tensile strength of $690 \mathrm{MPa}$, which is very close to the measured compressive ultimate strength $\sigma_{\mathrm{m}}=600 \mathrm{MPa}$. This value is about three times higher than the mentioned value for pure bulk titanium, which is considered to be in a slowly cooled condition.

The agreement of those values is based on the assumption of symmetry of the tensile and compression diagram.

\section{Conclusion \\ 5.1 Microstructure}

The two-dimensional plates sintered on the powder bed develop a microstructure which is composed of coarser primary needle-like $\alpha$-phase grains. The retained $\beta$-phase also transformed martensitically to $\alpha^{\prime}$. The so-called Widmannstätten microstructure corresponds to a slower cooling rate in the temperature region of the polymorphic transformation. The slower cooling is explained by the reduced heat transfer across the less compact powder bed compared to the underlying solid mass of sintered titanium in the threedimensional samples.

In the three-dimensional sintered specimen the microstructure looks the same as the one in the unsintered powder grains. Complete remelting and resolidification lead to large 


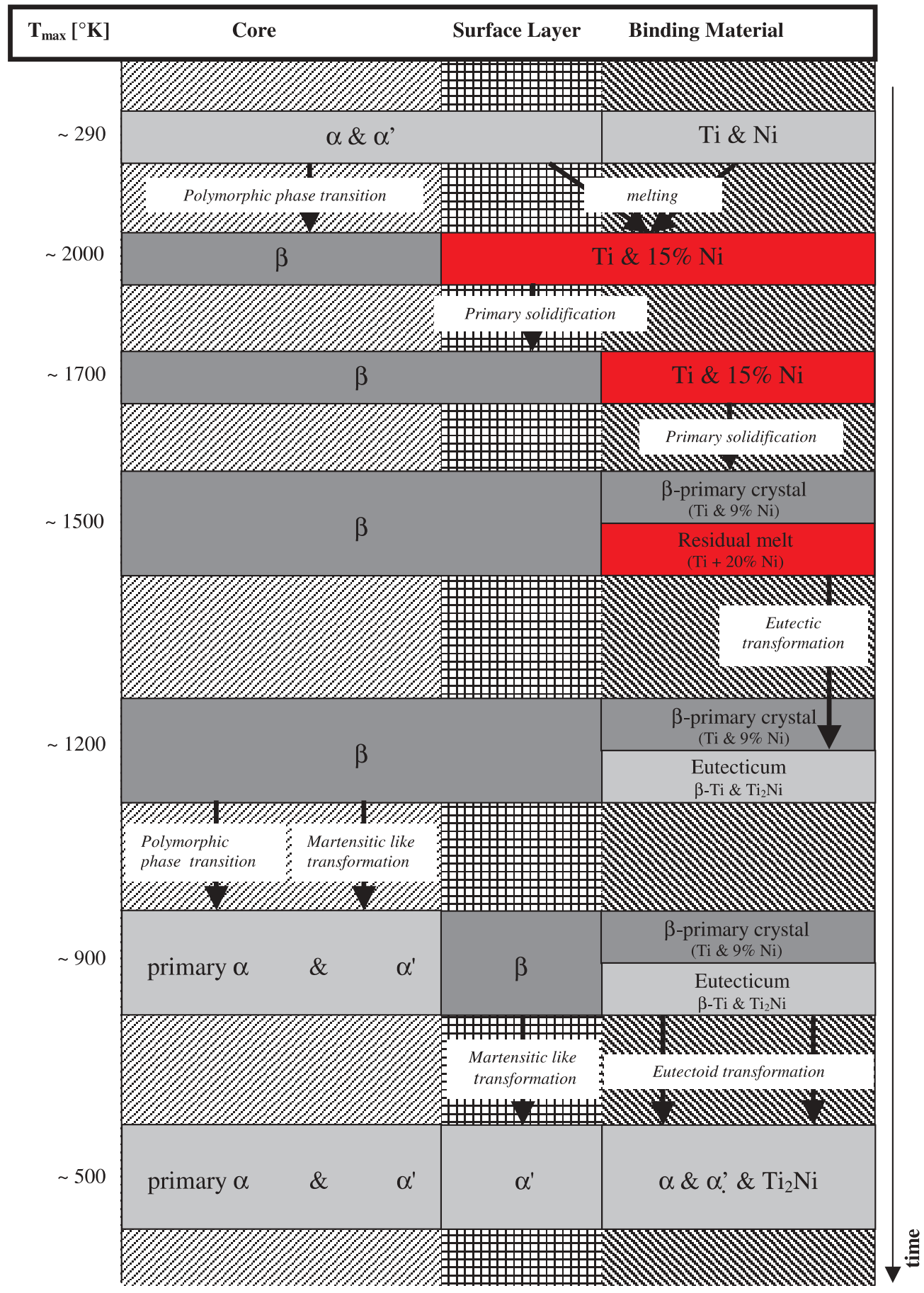

FIGURE 15 Schematic overview of the phase transitions during the pulsed sintering process homogeneous metallic particles in which the outline of the individual original powder grains cannot be visually detected. It is concluded that the cooling rate must be almost the same in the temperature range of the polymorphic transformation whether due to the powder manufacturing or to the laser processing. On the other hand, powder grains which were not completely remelted show such a zone at their surface. Obviously their microstructure at the surface is not the same as the one in the core. These powder grains are united by metallic material of different chemical composition to the binary system titanium and nickel having a eutectic or eutectoid microstructure.
The initial spherical titanium powder of commercial purity used for the selective laser sintering exhibits in the as-received condition a microstructure of very fine granular primary $\alpha$-phase grains in a matrix of $\alpha^{\prime}$ (martensitically transformed $\beta$-phase) due to the rapid solidification and the fast further cooling after the plasma atomisation process. The observed heterogeneous microstructure is a consequence of the fact that titanium is able to undergo a polymorphic transformation from the body-centred cubic to the hexagonal close-packed crystal structure while cooling from the solidification temperature. 


\section{$5.2 \quad$ Strength properties}

The microhardness is not affected very much by the laser processing of the pure titanium. Otherwise, in the observed eutectic or eutectoid microstructure binding individual original powder grains we notice an important increase of the microhardness. The latter is due to the presence of the intermetallic compound $\mathrm{NiTi}_{2}$.

ACKNOWLEDGEMENTS The authors would like to thank the Robert Mathys Stiftung for compressive strength testing and E. Kraehenbuehl for SEM and EDX analysis.

\section{REFERENCES}

1 M. Agarwala, D. Bourell, J. Beaman, H. Marcus, J. Barlow: Rapid Prototyping J. 1, 26 (1995)

2 P. Fischer, N.P. Karapatis, V. Romano, R. Glardon, H.P. Weber: Appl. Phys. A 74, 467 (2002)

3 P. Fischer, N.P. Karapatis, E. Boillat, V. Romano, R. Glardon, H.P. Weber: Acta Mater. 51, 1651 (2003)

4 G.S. Upadhyaya: Sintered Metallic and Ceramic Materials (Wiley, New York 2000)

5 W.G. Moffratt: Handbook of Binary Phase Diagrams, Vol. 5 (Genium, Genium Publishing Corporation 1994) [ISBN 0-931690-00-5]

6 S. Lampman: Wrought Titanium and Titanium Alloys, Handbook of Metals, Vol. 2, Properties and Selection: Nonferrous Alloys and SpecialPurpose Materials, Table 21, p.621. 10th edn. (ASM International, Metals Park, OH 1990) 